\title{
Examining whether Time Orientation Mediates or Moderates Age Effects on Goal Selection and Pursuit
}

Amy M. Knepple Carney

Follow this and additional works at: https://researchrepository.wvu.edu/etd

\section{Recommended Citation}

Carney, Amy M. Knepple, "Examining whether Time Orientation Mediates or Moderates Age Effects on Goal Selection and Pursuit" (2016). Graduate Theses, Dissertations, and Problem Reports. 7068. https://researchrepository.wvu.edu/etd/7068

This Thesis is protected by copyright and/or related rights. It has been brought to you by the The Research Repository @ WVU with permission from the rights-holder(s). You are free to use this Thesis in any way that is permitted by the copyright and related rights legislation that applies to your use. For other uses you must obtain permission from the rights-holder(s) directly, unless additional rights are indicated by a Creative Commons license in the record and/ or on the work itself. This Thesis has been accepted for inclusion in WVU Graduate Theses, Dissertations, and Problem Reports collection by an authorized administrator of The Research Repository @ WVU. For more information, please contact researchrepository@mail.wvu.edu. 


\title{
Examining whether Time Orientation Mediates or Moderates
}

Age Effects on Goal Selection and Pursuit

Amy M. Knepple Carney, M.S.

\author{
Thesis submitted \\ to the Eberly College of Arts and Sciences \\ at West Virginia University \\ in partial fulfillment of the requirements for the degree of
}

Master of Science in Psychology

Julie Hicks Patrick, Ph.D., Chair

Amy L. Gentzler, Ph.D.

Kevin T. Larkin, Ph.D.

Department of Psychology

Morgantown, West Virginia

2015

Keywords: Age, Time Orientation, Personal Goals, Mediation, Moderation Copyright 2015 Amy Knepple Carney 


\author{
ABSTRACT \\ Examining whether Time Orientation Mediates or Moderates
}

Age Effects on Goal Selection and Pursuit

Amy Knepple Carney

Future time perspective has been studied in a number of domains and shown to influence the associations among age and a range of personal, health and social goals (Carstensen et al., 1999; Cate \& John, 2007; Nurmi, 1992; Stahl \& Patrick, 2012). However, the past and present also matter. It is likely that future goals are affected by our present feelings or behaviors (Lewin, 1939), as well as by our future orientation. What is not clear, however, is whether and in what ways past and present orientation relate to current goals and age. The aim of the current study was to examine the associations among age, temporal orientations, and goal selection and pursuit. We examined these questions using data provided by 167 adults, ranging in age from 18 to 87 years $(M$ age $=39.8, S D=15.7)$. Age showed a positive, but weak, correlation with goals, showing that older adults had more goals than younger adults. Time orientations showed both moderating and mediating effects on the relationship between age and total number of goals a person was pursuing. Negative past time perspective mediated the relationship between age and goals, $F(2,164)=4.54, p=.012 ; R^{2}=.053$. The moderating effects between age and goals seem to be isolated to the people who have the highest levels of positive past, present, and/or future. This is important because how we feel about our present and our future, no matter the age, will help to determine how many goals we have. 


\section{Table of Contents}

Table of Contents....................................................................

I. Introduction......................................................................... 1

II. Current Study .............................................................. 9

A. Exploratory Research Questions and Hypotheses.............................. 9

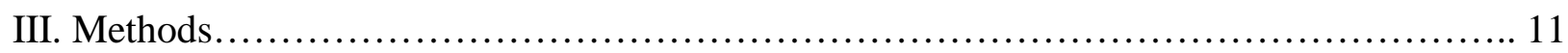

A. Procedure................................................................ 12

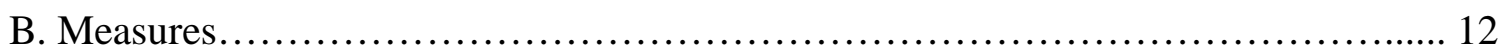

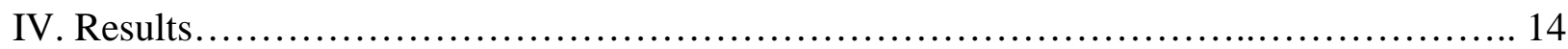

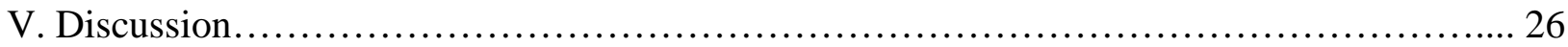

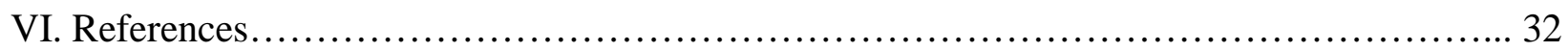

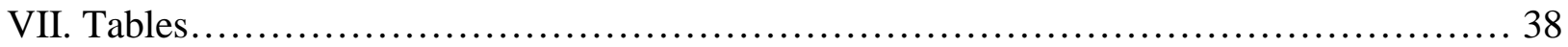

VII. Figures................................................................. 45

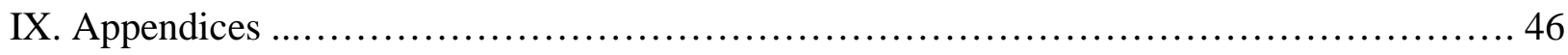




\section{Examining whether Time Orientation Mediates or Moderates}

Age Effects on Goal Selection and Pursuit

\section{Introduction}

\section{Overview}

Time orientation is defined as what has happened in the past, how we think about our future and the way in which we operate in terms of the present (Lennings, 2000), although the preponderance of research in this area has focused on future time. The human perception of time as either expansive or limited influences most behaviors and psychological processes (Carstensen, 2006). Across a variety of age groups and outcomes, an expansive future time perspective is associated with anticipation of having energy to complete tasks (Stolarski, Matthews, Posteck, Zimbardo, \& Bitner, 2014), social well-being (Coudin \& Lima, 2011), having more goals and exhibiting lower generativity (Brothers, Chui, \& Diehl, 2014), and less worry (Powers, Wisocki, \& Whitbourne, 1992). What is not clear, however, is whether and in what ways past and present orientation relate to such goals and age.

Some evidence suggests that these temporal dimensions of life exert profound effects on the types of goals we form and pursue. Within specific domains, research has focused on future time perspective and its influence on preference for social partners (Lang \& Carstensen, 2002), health behaviors and physical activity (Gellert, Ziegelmann, Lippke, \& Schwarzer, 2012; Stahl \& Patrick, 2012), on well-being (Coudin \& Lima, 2011) and on how motivated we are to work on future goals (Lens, Paixao, Herrera, \& Grobler, 2012). Clearly, our orientation to the future is an important influence on our thoughts, emotions, and behaviors. However, the past and present also matter. In fact, it is likely that future goals are directly shaped by our present feelings or behaviors (Lewin, 1939), which should be tied to our past feelings and behaviors. The past, 
present, and future may motivate people of different ages in different ways and may affect the goals they pursue.

\section{Defining Behavioral Goals}

According to Elliot and Fryer (2008), one way to define goals is that a goal involves focusing on the future and directing our behaviors to be proactive in obtaining that goal. In the lifespan development literature, Socioemotional Selectivity Theory (SST; Carstensen, 1992; Carstensen et al., 1999) also addresses goals. Initially, SST was predicated on the notion that expansive or restricted future time horizons would influence our social preferences. People are motivated by knowledge-acquisition and emotional-enhancement goals when selecting social partners. According to SST, those motivations differ as a function of how much time people feel they have left. For example, as time starts to seem more limited, adults lean more towards emotional goals rather than knowledge goals.

As research on SST has moved beyond social partners, broad support has been found across a variety of dependent variables, including goal selection and goal pursuit. Older adults tend to undertake fewer goals and these goals tend to be similar to each other compared to younger adults (Riediger \& Freund, 2006). Penningroth and Scott (2012) also found that relative to younger adults, older adults listed fewer goals and that those goals were focused on generativity and emotions. Rossi and Isaacowitz (2006) asked adults to generate a list of life domains that were currently important to them. Age differences emerged in the number of life domains generated, with older adults spontaneously listing a mean of 2.6 life domains, relative to middle-aged and younger adults, who each listed 3.9 domains on average. When presented with a checklist of 17 life domains, however, no age differences emerged in the number of domains evaluated as important, with means ranging from 11.03 to 11.68 domain. 
This finding is counter to the idea that with age, adults exhibit goal restriction in both the number and type of goals pursued. Baltes and Baltes (1990) proposed that in midlife, we start to focus on the time that we have left and this shift may motivate people to want to complete certain goals. Due to declining resources, including time, older adults may need to be more selective in the activities and goals they pursue, may strive to optimize their existing strengths and resources and may alter their behaviors in order to compensate for declining performance. Thus, choosing fewer goals may be a natural consequence of late life (Baltes \& Baltes, 1990).

As people age, the types of goals they focus on become less of individual needs and they become more generative (Brothers, Chui, \& Diehl, 2014). The types of goals also tend to change as people reach different milestones. Younger adults tend to be concerned with education and starting a family. Middle-aged adults have goals related to their children and gaining status, such as owning a home. Older adults tend to have goals related to their health, leisure time and more global concerns such as helping the next generation to succeed (Nurmi, 1992). Similarly, when examining the types of domains that adults spontaneously nominated as important, Rossi and Isaacowitz (2006) reported a few age differences, with younger adults being more concerned with academics and romantic partners and friends. However, when presented with a checklist of domains, few age differences emerged in the content of domains valued by adults, with the majority of all age groups deeming family and friends as important, as well as domains such as health, which $79 \%$ of younger adults, $89 \%$ of middle-aged adults, and $99 \%$ of older adults ranked as important.

\section{The Nature of Time Perspective}

Time is a powerful influence on how people behave (Zimbardo \& Boyd, 1999). Research has focused on measuring time orientation in different ways. Lang and Carstensen (2002) 
measure future time orientation as a unidimensional construct; people view time as either expansive or limited. The ways in which time is viewed influences whether a person will have knowledge-based or emotion-based goals. Cate and John (2007), on the other hand, give an alternative 2-factor model of time orientation, although still only focusing on future time. The two factors focus on opportunities, “My future is filled with possibilities,” versus on limitations, "I have the sense that time is running out.” It is proposed that middle-aged adults begin to focus more on limitations with advancing age and less on the opportunities (Cate \& John, 2007). Zimbardo and Boyd (1999) add to the concept of time perspective by looking at positive and negative past experiences, present hedonistic (pleasure seeking) and present fatalistic (helplessness or lack of control) and future behaviors. This may be a fuller understanding of time but still leaves out subjective feelings of the different time orientations.

An additional measure of time orientation, the Time Attitudes Scale (TAS; Mello \& Worrell, 2012), a subscale of the Adolescent Time Perspective Inventory, further expands the construct by identifying six factors assessing people's subjective feelings of time. These 6 are: past positive, past negative, present positive, present negative, future positive, and future negative. Among adolescents the six-factors of the TAS relate to other variables. For example, future negative had a moderate relationship with academic engagement, GPA, and fitting in at school. Present positive was associated with hope and optimism. Global self-esteem was related to all six factors, but perceived stress was only associated with present positive and negative factors. All six factors show different patterns of associations with other constructs and play important roles in how people feel about time.

Although the TAS was initially created for use in adolescence, recent evidence suggests that the field might benefit from using a modified version of this scale with adults. In order to 
make the TAS more appropriate for use with people older than adolescence, Pichayayothin (2014) modified the TAS; item 10 on the TAS, which is used to index negative future time perspective, substituting the phrase “...when I grow up” with “... in the future” (p.29). A large sample was collected $(n=400)$ and the factor structure of the TAS was examined across younger (19-32 years), middle-aged (40-55 years), and older adults (60-82 years). A multi-group analysis showed that the factor loadings of the TAS were invariant across the three age groups. Pichayayothin (2014) also found that all six subscales had a strong correlation with subjective well-being. Showing that the TAS may measure temporal well-being. In an age-mixed sample (Pichayayothin, 2014), construct validity of the TAS was shown to correlate with other time scales. Specifically, positive future was strongly correlated with focusing on opportunities $(\mathrm{r}=$ .8) whereas negative future was strongly correlated with focusing on limitations $(r=-.70)$ (Cate \& John, 2007). Both positive past and present were strongly correlated with Zimbardo and Boyd's (1999) past and present positive subscale ( $\mathrm{r}=.77$ and .32 , respectively). Moreover, negative past was associated with Zimbardo and Boyd's (1999) past negative $(r=-.44)$. Zimbardo (1990) has referred to time perspective as a construct that can show direct and indirect effects on people's thoughts. Thus, time perspective may directly affect behavior but may also be a mediator for other variables. Researchers have studied the direct effects of time perspective in terms of how much time a person subjectively feels like they have left (Rakowski, 1986) or how open-ended a person feels their life is and whether they have knowledge or social goals (Carstensen et al., 1999). Research looking at the direct effect of time has found that when people feel as if their life is fragile, through potential epidemics like SARS and HIV, they look for emotional goals, no matter their age (Carstensen \& Fredrickson, 1998; Fung \& Carstensen, 
2006) An expansion on this is when people assess the opportunities or limitations they feel may be available to them as they age (Cate \& John, 2007).

Yet another way to study time perspective is to assess people’s subjective evaluation, positive or negative, of their past, present, and future (Mello \& Worrell, 2012). Previous studies of the TAS (Mello \& Worrell, 2012) indicate that the scale has a six-factor structure used to assess people’s subjective feeling of time. Each of the six perspectives may, invariably, lead to different motivations and goals that a person has.

The indirect effect of time perspective also has been studied. Based on SST (Carstensen et al., 1999; Lang and Carstensen, 2002) and models in the extant literature (Gellert et al., 2012) there is evidence that future time perspective mediates the effects of age on goals. Stahl and Patrick (2012) found that future time perspective mediated the relationship between age and health related goals. Another study showed that positive attitudes towards the future had a mediational effect between motivation and a student's judgement of academic achievement (de Volder \& Lens, 1982). Moreover, based on Spreng and Levine (2006), past orientation is also expected to influence the association between age and goals because older adults think more about their past, middle-aged more about the present and younger adults think more about the future.

There is also suggestive evidence of an interaction or moderating effect of time. Time orientation may act differently across age groups in that older adults define the future in much more limited ways than younger adults and this has an effect on the number and types of goals they pursue (Fingerman \& Perlmutter, 2001). Past and present may also play a role across the life span. It has consistently been shown that once we are in middle adulthood we are more oriented towards the past (Powers, Wisocki \& Whitbourne, 1992) and satisfaction with our past tends to 
be associated with age (Ryff, 1991). Based on Lennings (2000), present orientation is expected to moderate the effects of age on goals because older adults think about the present in more concrete terms than the future and base their goals on what is happening now rather than what will happen.

\section{Age Effects in Time Perspective}

Evidence suggests that people tend to think about their near future, the next few months, more often than their near past, the past few months (Fingerman \& Perlmutter, 2001). However, there are clear interactions with age. For example, younger adults may be more focused on the future compared to past or present (Tonn \& Conrad, 2007). Younger adults often think about their future, about one thought every 16 minutes, and those thoughts take on a variety of different themes, including work, planning, and errands (D’Aegembeau, Renaud, \& Van Der Linden, 2011). Relative to middle-aged and older adults, younger adults worry about their future more and view the future as more open and ambiguous (Brothers, Chui, \& Diehl, 2014). Younger adults also focus more on future opportunities compared to middle-aged and older adults, who do not differ from each other (Cate \& John, 2007). Middle-aged and older adults, on the other hand, tend to focus on their past and present experiences.

Adults tend to be more satisfied and focused on their past as they get older (Ryff, 1991). Older adults tend to be more oriented towards the past and present compared to the future. Worrying about the future, however, is higher among older adults’ who hold less favorable views of the future (Powers et al., 1992). Older adults also focus more on future limitations compared to younger and middle-aged adults, who do not differ from each other (Cate \& John, 2007). Consistent with these findings, Lennings (2000) found that when older adults answered openended questions about time, they tended to focus on the present and, to a smaller extent, the past. 
When older adults do think about their futures, they tend to think about days or months compared to younger adults who think about the future in terms of years (Fingerman \& Perlmutter, 2001). The way we think about time has an impact on the goals we have for our future and the things that we feel we still have time to accomplish.

\section{Age, Time perspective, and Goal Domains}

Age effects in the types of goals people have may also be related to whether a person pulls from the past or looks to the future. Older adults tend to draw from a broader range of goals than do younger adults; younger adult's goals tend to center on knowledge-based goals (Penningroth \& Scott, 2012). Middle-aged and older adults, however, are more likely to engage in emotion-regulation goals and generativity goals compared to younger adults (Lang \& Carstensen, 2002).

Specifically, adults who feel that their time is limited are less likely to engage in healthrelated goals compared to people with a more expansive future perspective. Gellert, Ziegelmann, Lippke, and Schwarzer (2012) found that the influence of age on health behaviors is mediated by future time perspective. A person who feels more positively or expansive about their future is more willing to make more health-related goals. Across age, adults who feel that their time is more open are more likely to make and pursue physical activity goals and to engage in physical activity compared to adults who feel more limited (Stahl \& Patrick, 2012).

Most of the research assessing age differences in goals has focused on goals within a specific researcher-identified domain. Rossi and Isaacowitz (2006), however, asked adults to generate a list of life domains that were currently important to them. Age differences emerged in the number of life domains generated, with older adults listing about 1.3 fewer domains than middle-aged and younger adults, who did not differ from each. However, when presented with a 
checklist of 17 life domains, no age differences were detected, with means ranging from 11.03 to 11.68 domains selected as being of current importance. Thus, relative to the open-ended format, the checklist was better at eliciting a broader range of important domains across all three age groups.

\section{Limitations to the current literature}

Although studies have found mediation effects for future time perspectives, no studies have examined these effects for past and present time perspectives. Stahl and Patrick (2012) found that future time perspective is a mediator for age and physical activity, with no direct effect of age on physical activity. Similarly, it was found that future time perspective, defined as how expansive we see our future, had mediating effects for age and health (Gellert et al., 2012).

Neither of these studies examined past or present time orientation nor whether those orientations mediate health and other behavioral goals. This is a gap in time orientation research because different age groups focus on different aspects of time (past and present) and those times may play a larger role in our goals than only future time.

\section{Current Study}

The current study examined the associations among chronological age, time orientation, and the number and types of goals adults have.

\section{Exploratory Research Questions and Hypotheses}

Goals. H1: Based on the work by Baltes and Baltes (1990) suggesting that with age people become more restrictive in the goals they have, we expected a negative association between age and number of goals. 
H2: Based on SST (Carstensen, Issacowitz, \& Charles, 1999), we expected that age would be associated with the types of goals adults express, such that older adults will be associated with more emotion-based goals.

Time Perspective. H3a: Replicating Spreng \& Levine, 2006, it was hypothesized that older age would be associated with having a more positive orientation towards the past. H3b: Based on SST (Carstensen, Issacowitz, \& Charles, 1999), it was hypothesized that older age would be associated with having a less positive orientation to the future.

Time Perspective and Goals. H4a: Based on previous research (de Volder \& Lens, 1982; Lennings \& Gow, 1997), it was expected that positive future perspectives would completely mediate the effect of age on the number of goals currently being pursued. H4b: Based on previous research (de Volder \& Lens, 1982; Lennings \& Gow, 1997), it was expected that both negative future time perspectives would completely mediate the effect of age on the number of goals currently being pursued.

E1a: Based on Baltes and Baltes (1990) and how past and present time perspectives are more important to middle-aged and older adults, it is expected that positive past and negative past will partially mediate the effects of age on the number of goals currently being pursued. E1b: Based on Baltes and Baltes (1990) and how past and present time perspectives are more important to middle-aged and older adults, it is expected that positive present and negative present will partially mediate the effects of age on the number of goals currently being pursued. E2: Because time orientation may act differently across age groups (Fingerman \& Perlmutter, 2001), it was expected that past, present, and future time perspective would moderate age effects on the number of goals a person is currently pursuing. 


\section{Method}

\section{Power analysis}

In order to determine the sample size needed to provide sufficient power for our analyses, a formal power analysis was conducted. A formal power analysis, implemented in G*Power (Erdfelder, Faul \& Bechner, 1996), suggested that $n=109$ would be sufficient to detect mediumsized effects $\left(f^{2}=.15\right)$ in a 3 -variable regression equation at (power $=.80, p<.05$ ). In general, power analyses are not well-suited to determine the number of participants needed in order to detect medium-sized effects moderation and mediation regression (Hayes, 2012). Thus, bootstrapping methods are often employed as a means to bolster confidence in results. Boot-strapping is also better and renders p-value adjustment unnecessary. Thus, we used 1000 boot-strapping samples because it allows for higher power, to bolster the confidence, and allowed us to assess both the mediation and indirect effects (Hayes, 2009).

\section{Participants}

Participants were drawn from community-dwelling adults who responded to print and electronic ads to complete an online prescreen survey for a health coaching study. All participants were offered \$5 to complete the survey. A total of 167 adults from a pool of 196 had complete data on the items of interest. Within those 167 adults, completion rates for individual items was high; because missingness was low for the 167 adults, we used individual item mean imputations for 7 data points. Respondents consisted of 44 men (26.3\%) and 123 women (73.7\%), with an average age of $M=39.8$ years ( $S D=15.7$, range $18-87$ years). Participants included younger $(n=78)$, middle-aged $(n=50)$, and older adults $(n=39)$. 


\section{Procedure}

Participants completed a 25-page survey assessing general and perceived physical and mental health, decision making, technology use, goals, personality, social exchanges, time attitudes, and basic demographic information. Participants completed the survey in about 38 minutes $(S D=31.4$, range 25-60). Although the larger study included a variety of measures, only those measures related to the current study are discussed in this report.

\section{Measures}

Number of Goals. Participants were presented with a list of 31 behaviors, see appendix 1, representing typical goals adults have. Because there are no scales cataloging goals that adults typically pursue, we compiled items from the broader research on behavior change goals in the domains of: health-promotion, illness prevention, personal development, interpersonal relations, spiritual growth, and cognitive development. For each item, adults indicated whether the item was a personal goal and, if it was a goal, whether it was currently being pursued or completed, whether the goal had been started but abandoned $(M=2.07, S D=2.59)$, or whether the item was a goal that had not yet been started $(M=4.82, S D=5.34)$. The number of goals each participant was pursuing were added for an overall number of current goals. On average, participants had $9.8(S D=6.5)$ goals they were currently pursuing, including: lose weight $(42.5 \%)$, gain weight (3\%), increase exercise (48.5\%), reduce tobacco use (7.2\%), reduce alcohol use (10.2\%), walk more (44.9\%), eat healthier foods (58.7\%), reduce, re-use or recycle $(40.1 \%)$, sleep more (27.5\%), sleep less (5.4\%), be more social (28.1\%), study more (19.8\%), save more money (38.3\%), spend less money (40.7\%), be kinder to others (49.7\%), be kinder to one's self (43.1\%), control one’s anger (29.9\%), be happier (56.9\%), be more assertive (26.9\%), meditate or relax (26.9\%), be more spiritual (25.1\%), be more religious (18.6\%), develop a new skill 
(31.7\%), deal better with stress (31.1\%), reduce one’s stress (32.3\%), make better decisions (28.7\%), improve one’s memory (24.6\%), volunteer in the community (25.1\%), give money to charities (23.4\%), be more grateful (47.3\%), and appreciate beauty (40.1\%).

Types of Goals. The 31 goals were subjected to a card sort by 12 panelists to check for agreement with the researcher's categorization. The panelists had an 85\% agreement with the categories of the goals and in this way 4 main factors emerged: physical health, socioemotional development, spiritual/religious, cognitive, and distractor/low agreement goals. The physical health factor consisted of 9 goals: lose weight, gain weight, increase exercise, reduce tobacco use, reduce alcohol use, eat healthier foods, sleep more, sleep less, and walk more. These items were combined to form a single scale indexing the breadth of a person's physical health goals; a mean of 2.48 goals $(S D=1.7)$ was observed. See Table 1 for correlations between age and individual physical health goals.

Socioemotional development goals included 12 behaviors: be kinder to others, be more assertive, be more social, control your anger, be happier, meditate or relax, develop a new skill, deal with stress better, reduce your stress, volunteer in the community, give money to charities, and be kinder to yourself. These items were combined to form a single scale indexing the breadth of social interaction goals, resulting in a mean of 4.05 goals $(S D=3.2)$. See Table 2 for correlations between age and individual socioemotional development goals.

Four behaviors represented spiritual/religious goals: appreciate beauty, be more grateful, be more spiritual, and be more religious. These items were combined to form a single scale indexing the breadth of psychological goals and resulted in a mean count of 1.31 goals $(S D=$ 1.33). See Table 3 for correlations between age and individual spiritual/religious goals. 
Two behaviors characterized cognitive goals, including: make better decisions, and improve one’s memory. Adults expressed a mean of .53 cognitive goals $(S D=.77)$. See Table 4 for correlations between age and individual cognitive goals.

Four goals were not included in any categories because they were considered to be distractor goals or agreement level between the panelists was low ( $<30 \%)$, those goals included: reduce, reuse, or recycle, study more, save more money, and spend less money.

The 31 goals were subjected to an exploratory principal components factor analysis, followed by a confirmatory factor analysis. The final analysis yielded two uninterpretable factors. Because the 31 behavioral goals were specifically chosen to represent over-arching domains, we proceed with the card sort approach. See appendix 2 for factor analysis results, as well as the mediation and moderation results with those factors.

Time Perspective. We used Pichayayothin’s (2014) modification of the Time Attitudes Scale (TAS;Mello \& Worrell, 2012) to assess six aspects of time orientation. The TAS consists of 30 items, each scored on a 5-point Likert-type scale. Higher scores on scales represent higher levels of the underlying construct. Similar to Pichaysyothin (2014), Cronbach’s alpha coefficients of the subscales in the current were acceptable, with negative past (.92), positive past (.92), negative present (.88), positive present (.94), negative future (.85) and positive future (.93).

\section{Results}

\section{Bivariate Associations}

To ascertain whether age was associated with the total number of goals, we examined the Pearson correlations, shown in Table 5. A small but significant positive association between age and the number of current goals $(r(165)=.17, p<.05)$ was observed. Similarly, a significant positive association emerged between age and socioemotional goals $(r(165)=.18$, $p<.05)$, 
between age and cognitive goals $(r(165)=.18, p<.05)$, and between age and the spiritual/religious goals $(r(165)=.22, p<.01)$. Significant associations between age and physical health goals $(r(165)=.08)$ failed to emerge. Associations among age and time perspectives were assessed. There was a small significant negative correlation between age and negative past $(r(165)=-.17, p<.05)$. However, age was not significantly correlated with any of the other time perspectives, with coefficients ranging from .01 to .11.

The shaded cross-section of Table 5 shows the associations among the six aspects of the time perspective scale. As shown, moderate to high correlations were observed within the temporal perspectives, with the positive and negative aspects of each correlating between .73 and .89. Similarly, the valences across the three temporal orientations were also highly correlated.

\section{Mediation Analyses with Number of Goals}

The traditional approaching to mediation (Baron \& Kenny, 1986) says that there needs to be a significant relationship between the predictor variable $(\mathrm{X})$ and mediation variable $(\mathrm{M})$. If this relationship is not shown, then the analysis stops. In order to more closely examine the association between age, time, and total number of goals (see Appendix 1 for goals), we conducted a series of mediation analyses. The traditional Baron and Kenny (1986) approach, causal step, to mediation has been shown to have low statistical power in testing because of inflated error due to use of multiple tests (Fritz \& MacKinnon, 2007). Therefore, PROCESS was used for these analyses because it allows for increased power through boot-strapping, to bolster the confidence, and allows us to assess both the mediation and indirect effects (Hayes, 2009).

The relation between age and the total number of goals was mediated by negative past time perspective, $F(2,164)=4.54, p=.012 ; R^{2}=.05$. Age uniquely contributed to the variance explained in negative past time perspective (path a), [b=-.06, $p<.05]$. As age increases feelings 
of negative past decrease. Negative past time perspective uniquely contributed to the variance explained in number of goals (path $\mathrm{b}$ ), $[b=-.19, p<.05]$. As negative past increases a person has less current goals they are working on. Age uniquely accounted for variance in number of goals (path c), [b=.07, $p<.05]$. As age increases a person has more goals. However, when negative past was included in the model (path c'), age no longer uniquely contributed to the variance in number of goals $[b=.59, p=.08]$, showing a mediation. Showing that the relationship between age and goals is an indirect relationship through how negative a person feels towards their past. See Figure 1 for the significant coefficients and a model summary.

However, none of the other time perspectives mediated the relationship between age and goals because there was no relationship between age and those time perspectives. However, by using PROCESS, relations were still assessed, after finding that path a was not significant, using a linear regressions with age and the different time perspectives as the predictors. See Table 6 for all mediation regression results predicting total number of goals.

The model including age and positive past significantly predicted number of goals, $F(2,164)=4.33, p=.015 ; R^{2}=.05$. However, inspection of the unstandardized betas showed that only age exerted direct effects on goals $[b=.064, p<.05]$. As age increases a person has more goals. Positive past did not uniquely contribute to the variance accounted for in the number of current goals $[b=.21, p=.06]$.

Similarly, age and positive present significantly predicted number of goals, $F(2,164)=$ $8.68, p=.001 ; R^{2}=.10$. However, inspection of the unstandardized betas showed that only positive present exerted direct effects on goals $[b=.34, p<.01]$. As positive present increases a person has more current goals they are working on. Age did not uniquely contribute to the variance accounted for in the number of current goals $[b=.06, p=.06]$. 
Age and negative present significantly predicted number of goals, $F(2,164)=5.86, p=$ $.004 ; R^{2}=.07$. However, inspection of the unstandardized betas showed that only negative present exerted direct effects on goals $[b=-.16, p<.01]$. As negative present increases a person has less current goals they are working on. Age did not uniquely contribute to the variance accounted for in the number of current goals $[b=.06, p=.051]$.

Age and positive future significantly contributed to the variance accounted for in the number of current goals, $F(2,164)=10.17, p<.001 ; R^{2}=.11$. Inspection of the unstandardized betas showed that both positive future $[b=.44, p<.01]$ and age $[b=.07, p<.05]$ exerted direct effects on goals. As positive future and age increase, a person has more current goals they are working on.

Age and negative future significantly contributed to the variance accounted for in the number of current goals, $F(2,164)=6.46, p=.01 ; R^{2}=.07$. Inspection of the unstandardized betas showed that both negative future $[b=-.35, p<.01]$ and age $[b=.07, p<.05]$ exerted direct effects on goals. As negative future increases a person has less current goals they are working on but as age increases a person has more goals they are working on.

\section{Mediation Analyses with Goal Domains}

Because goal domains are important to the overall understanding of the goals people have for their future, mediation analyses were run on physical health goals and socioemotional goals. However, we focus solely on physical health goals and socioemotional goals, excluding the spiritual and the cognitive goals, because the latter were poorly distributed and were not improved with data transformation measures.

Physical health. The relation between age and the total number of physical health goals was mediated by negative past time perspective, $F(2,164)=5.60, p=.005 ; R^{2}=.06$. Age 
uniquely contributed to the variance explained in negative past time perspective (path a), $[b=$ $.06, p<.05]$. Negative past time perspective uniquely contributed to the variance explained in number of physical health goals (path $\mathrm{b}$ ), $[b=-.08, p<.05]$. However, age did not uniquely contribute to the variance explaining number of physical health goals (path $c$ ), $[b=.00, p=.58]$, showing a mediation. The relation between age and total number of health goals is through the path of negative past time perspective.

However, none of the other time perspectives mediated the relationship between age and goals because there was no relationship between age and those time perspectives. However, by using PROCESS, relations were still assessed, after finding that path a was not significant, using a linear regressions with age and the different time perspectives as the predictors.

The model including age and positive past significantly predicted number of physical health goals, $F(2,164)=3.63, p=.02 ; R^{2}=.04$. However, inspection of the unstandardized betas showed that only positive past exerted direct effects on goals $[b=.07, p<.05]$. Age did not uniquely contribute to the variance accounted for in the number of physical health goals $[b=.01$, $p=.41]$.

Similarly, age and positive present significantly predicted number physical health goals, $F(2,164)=11.75, p<.001 ; R^{2}=.13$. However, inspection of the unstandardized betas showed that only positive present exerted direct effects on goals $[b=.12, p<.01]$. Age did not uniquely contribute to the variance accounted for in the number of physical health goals $[b=.00, p=.50]$.

Age and negative present significantly predicted number of physical health goals, $F(2,164)=6.68, p=.002 ; R^{2}=.08$. However, inspection of the unstandardized betas showed that only negative present exerted direct effects on goals $[b=-.09, p<.01]$. Age did not uniquely contribute to the variance accounted for in the number of physical health goals $[b=.01, p=.45]$. 
Age and positive future significantly contributed to the variance accounted for in the number of physical health goals, $F(2,164)=8.09, p<.001 ; R^{2}=.09$. Inspection of the unstandardized betas showed that only positive future exerted direct effects on physical health goals, $[b=.12, p<.01]$. Age did not uniquely contribute to the variance accounted for in the number of physical health goals $[b=.01, p=.27]$.

Age and negative future significantly contributed to the variance accounted for in the number of physical health goals, $F(2,164)=8.41, p<.001 ; R^{2}=.09$. Inspection of the unstandardized betas showed that only negative future exerted direct effects on physical health goals, $[b=-.13, p<.01]$. Age did not uniquely contribute to the variance accounted for in the number of physical health goals $[b=.01, p=.37]$.

\section{Moderation Analyses with Number of Goals}

We determined that the data met the underlying assumptions of the General Linear Model prior to using PROCESS (Hayes, 2012) to test whether the various time perspectives moderated the association between age and the number of current goals. When significant omnibus effects were detected but there were no unique contributions based on the unstandardized regression weights, we examined the regions of significance via the Johnson-Neyman ( J-N) technique (Hayes \& Matthes, 2009; Johnson \& Neyman, 1936). Borrowed from the ANOVA framework, the J-N technique can be used to probe the interaction to assess at which levels of the moderator a significant effect is observed (Hayes, 2013).

Results of the six moderated regression models are presented in Table 7. In the equation examining whether positive past moderated the effects of age on goals, an omnibus effect was detected, $F(3,163)=3.14, p<.05, R^{2}=.05$. However, neither age $(b=-.04, p=.76)$, positive past $(b=-.01, p=.96)$, nor the interaction $(b=.01, p=.38)$ uniquely contributed to the overall 
effect. The J-N region of significance for positive past was toward the middle of the scale, between the scores of 17.07 and 22.54 (5-25 scale range). Additional post hoc J-N analyses showed that this effect was localized to those in midlife, approximately ages 40 to 55 years. Thus, middle-aged adults who scored in the moderate but not extreme levels of positive past endorsed more total goals than their counterparts, with the effect ranging from .22 to .31 among the middle-aged adults.

Potential moderating effects of negative past on the relation between age and the number of total goals were examined, with $F(3,163)=3.21, p<.05, R^{2}=.06$. Neither age $(b=.11, p=$ .15 ), negative past ( $b=-.02, p=.92)$, nor the interaction $(b=-.01, p=.45$ ) uniquely contributed to the overall effect. The J-N technique showed no discernable pattern of negative past as a moderator, although a significant effect of negative past on the age to goals association was detected for middle-aged adults between the ages of approximately 37 to 54 years, with the effect ranging from -.19 to -.27, respectively, suggesting that middle-aged adults with higher perceptions of negative past endorsed fewer total goals than other adults.

Positive present moderated the relation between age and the number of current goals, $F(3,163)=6.68, p<.01, R^{2}=.11$. However, neither age $(b=-.12, p=.29)$, positive present $(b=$ -.03, $p=.89)$, nor the interaction $(b=.01, p=.11)$ uniquely contributed to the overall effect. Results of the J-N technique showed that the region of significance was at the upper range of positive present, on all scores greater than 18.84 (5-25 scale range). The effect was significant for adults older than age 27 years. Thus, beyond the period of emerging adulthood, adults with more positive perceptions of their present endorsed more total goals. The effect ranges in size from .23 to .84 . 
Moderating effects of negative present on the relation between age and the number of total goals were detected. Again, the omnibus test was significant, $F(3,163)=3.89, p<.05, R^{2}=$ .07 , but neither age $(b=.06, p=.52)$, negative present $(b=-.27, p=.35)$, nor the interaction $(b=$ $.000, p=.98)$ uniquely contributed to the overall effect. The J-N technique showed no moderating effect of negative present, although a significant effect was observed among adults ages 26 through 50 years, with effect sizes near -.26. Thus, younger and early mid-life adults expressing lower levels of negative present endorsed more total goals than their counterparts.

Positive future moderated the relation between age and the number of current goals, $\mathrm{F}(3$, $163)=6.95, p<.01, R^{2}=.11$. Neither age $(b=-.04, p=.79)$, positive future $(b=.22, p=.49)$, nor the interaction $(b=.01, p=.46)$ uniquely contributed to the effect. Further assessment with the J-N technique showed that age and positive future interacted to predict goals at the highest levels (scores greater than 18.55) of positive future, although the effect was not observed for emerging adults younger than age 22 years. Among adults beyond emerging adulthood, positive future perceptions were associated with more total goals, with effect sizes ranging from .16 for adults in their mid-20s, to .44 for adults around age 40 years, and .52 for adults over age 55 years.

Likewise, negative future moderated the association between age and number of goals, $F$ $(3,163)=4.49, p<.01, R^{2}=.08$, although neither age $(b=.12, p=.14)$, negative future $(b=$ $.11, p=.74)$, nor the interaction $(b=-.01, p=.45)$ uniquely contributed to the overall effect. The J-N showed that age and negative future interacted to predict goals only at the lowest levels of negative future, when scores were between 5.58 and 10.11 (5-25 scale range). This effect was specific to middle-aged adults roughly between the ages of 29 to 67 years, with effect sizes 
ranging from -.29 to -.53 . Adults in this age range who expressed more negative views about their future endorsed fewer total goals than did their counterparts.

\section{Moderation Analyses with Goal Domains}

Because we also sought to understand the potential moderating effects of temporal perspectives within specific goal domains, we conducted parallel analyses to those with the total number of goals using the goal domains obtained from our card sort panel.

Physical Health. Moderating effects of positive past on the relation between age and the number of physical health goals failed to be detected, $F(3,163)=2.41, p=.07$. Because this equation was not significant, we did not conduct post hoc analyses.

Negative past moderated the relation between age and the number of physical health goals, $F(3,163)=3.74, p<.05, R^{2}=.06$. However, neither age $(b=.01, p=.61)$, negative past ( $b=-.06, p=.34)$, nor the interaction $(b=.00, p=.76)$ uniquely contributed to the effect. Using the J-N technique, no ranges of significance were detected for negative past. However, higher perceptions of negative past related to fewer health goals for adults up to about age 61 years, with effect sizes hovering around -.07.

Moderating effects of positive present on the relation between age and the number of physical health goals emerged, $F(3,163)=8.77, p<.01, R^{2}=.14$. Neither age $(b=-.04, p=.17)$, positive present $(b=.02, p=.75)$, nor the interaction $(b=.01, p=.11)$ uniquely contributed to the effect. No regions of significance for positive present were identified by the J-N technique. The post hoc J-N test did identify significant effects for adults older than age 19 years, with effects increasing from .07 in young adulthood to .09 around age 40 years, to .12 for adults in their mid50s. The effects were even stronger for adults in their late 60 s through 80 s, with effect sizes 
ranging from .14 to .17. Thus, perceptions of positive present were associated with more health goals across the adults age span and were highest for those over age 70 years.

Negative present moderated the relation between age and the number of physical health goals, $F(3,163)=4.56, p<.01, R^{2}=.08$. However, neither age $(b=.02, p=.41)$, negative present $(b=-.05, p=.50)$, nor the interaction $(b=.00, p=.55)$ uniquely contributed to the effect. The J-N technique revealed no regions of significance for negative present. However, the J-N technique identified effects through age 59 years, with younger adults and middle-aged adults who expressed higher negative present perceptions endorsing fewer health goals (effect $=-.07$ ) Moderating effects of positive future on the relation between age and the number of physical health goals emerged, $F(3,163)=5,67, p<.01, R^{2}=.09$. Neither age $(b=-.03, p=50)$, positive future $(b=.04, p=.61)$, nor the interaction $(b=.00, p=.35)$ uniquely contributed to the effect. The J-N technique failed to detect any regions of significance for positive future. The association did emerge among adults older than age 24 years, however, with effect sizes ranging from .06 to .12. Adults with more positive future perceptions endorsed more physical health goals than their counterparts.

Negative future also moderated the relation between age and the number of physical health goals, $F(3,163)=6.05, p<.01, R^{2}=.10$. Neither age $(b=.03, p=.16)$, negative future $(b$ $=-.04, p=.69)$, nor the interaction $(b=.00, p=.25)$ uniquely contributed to the effect. Although the J-N technique did not reveal any regions of significance for negative future, such a region was identified for all but the oldest adults (age 80+) in our sample. Effect sizes ranged from -.09 to -.11. Adults with higher negative future perspectives reported fewer health goals.

Socioemotional Goals. Positive past moderated the effects of age on the number of socioemotional goals, $F(3,163)=3.24, p<.05, R^{2}=.06$, although neither age $(b=.00, p=.98)$, 
positive past ( $b=.02, p=.87)$, nor the interaction $(b=.00, p=.53)$ uniquely contributed to the overall effect. The J-N technique showed that the region of significance for positive past was for scores in the moderate range of the scale, at scores between 16.14 and 21.84 (5-25 scale range). Additional J-N analyses showed that this effect was specific to middle-aged adults between the ages of 40 and 48 years, with effect sizes between .11 and .12. Thus, middle-aged adults scoring in the moderate range for positive past report more socioemotional goals than their counterparts.

Similarly, negative past moderated the relation between age and the number of socioemotional goals $F(3,163)=3.08, p<.05, R^{2}=.05$. Neither age $(b=.05, p=.23)$, negative past ( $b=-.04, p=.74)$, nor the interaction $(b=.00, p=.67)$ uniquely contributed to the overall effect. The J-N technique showed no discernable pattern of negative past as the moderator, nor were regions of significance identified for age.

Positive present moderated the effects of age on socioemotional goals, $F(3,163)=4.50$, $p$ $<.05, R^{2}=.07$, although neither age $(b=.00, p=.98)$, positive present $(b=.06, p=.62)$, nor the interaction $(b=.00, p=.56)$ uniquely contributed to the overall effect. The $\mathrm{J}-\mathrm{N}$ technique revealed that significant effects were present in moderate but not extreme scores on positive present, when scores range between 17.77 and 23.00 (5-25 scale range). Adults between the ages of 27 and 61 were especially likely to show this effect, with effect sizes ranging from .12 to .18. Younger and Middle-aged adults expressing higher levels of positive present endorsed more current socioemotional goals than their counterparts.

Moderating effects of negative present on the relation between age and the number of socioemotional goals were detected, $F(3,163)=3.95, p<.01, R^{2}=.07$, but neither age $(b=.00$, $p=.89)$, negative present $(b=-.24, p=.09)$, nor the interaction $(b=.00, p=.35)$ emerged as unique predictors of such goals. Post hoc analyses with the J-N technique revealed a significant 
effect at moderate levels on the negative present scale for scores between 11.77 and 19.38 (5-25 scale range). Moreover, the J-N technique revealed that the effect was primarily observed in adults younger than age 42 years. Effect sizes ranged from -.10 at age 42 to -.18 among adults aged 18 years. Thus, younger and early middle-aged adults who expressed moderate levels of negative present endorsed fewer socioemotional goals.

Positive future moderated the relation between age and the number of socioemotional goals, $F(3,163)=5.85, p<.01, R^{2}=.10$. Neither age $(b=.03, p=.70)$, positive future $(b=.17$, $p=.27)$, nor the interaction $(b=.00, p=.90)$ uniquely contributed to the effect. Further assessment with the $\mathrm{J}-\mathrm{N}$ technique shows that the region of significance for positive future was on scores between 17.12 and 23.08 (5-25 scale range). In addition, the ages between 20 years and 63 years were identified as regions of significance; younger and middle-aged adults expressing moderate to high positive future perspectives endorsed more socioemotional goals. Effect sizes ranged between .18 and .20 .

Negative future moderated the age-to-goal relation, with $F(3,163)=3.50, p<.05, R^{2}=$ .06. Neither age $(b=.04, p=.29)$, negative past $(b=-.10, p=.55)$, nor the interaction $(b=.00$, $p=.82$ ) uniquely contributed to the overall effect. The J-N technique showed no discernable pattern of negative future as the moderator. However, the ages between 33 and 48 years were identified as regions of significance, with effect sizes ranging from -.13 to -.14. Adults in early midlife who expressed higher levels of negative perceptions of the future reported fewer socioemotional goals than did their counterparts.

For additional, non-proposed, exploratory analyses assessing physical and mental health, see Appendix 3. 


\section{Discussion}

Time perspective and age are related to goal pursuit. However, much of this research has focused on only a single goal domain. For example, previous research assessing SST (Carstensen et al., 1999) examined social interaction preferences, with knowledge-related and emotionrelated goals as primary motivations. Age differences have been detected, with younger adults favoring knowledge-related motivations and older adults espousing socioemotional motivations for their social interaction partners and goals. Rossi and Isaacowitz (2006) reported relatively few age differences when adults self-generated domains in which they pursue goals. When asked to use a checklist of various domains, however, age differences emerged for both the number and types of domains. Although Rossi and Isaacowitz (2006) added to the field by explicitly comparing different methods of assessing goal domains, they did not investigate specific behavioral goals within those domains. Of note, age differences in the number of domains endorsed on the checklist emerged only when self-assessed health was statistically controlled. When self-assessed health was controlled, younger adults endorsed fewer domains than middleaged and older adults. The current research adds an essential component to this research by moving beyond global domains, the general, to specific behavioral goals.

Contrary to previous research, and hypothesis 1 , that older adults become more focused on emotional goals and have few goals (Riediger \& Freund, 2006), our results are similar to the checklist condition of Rossi and Isaacowitz (2006), with our correlations supporting small, positive associations between age and the number of goals endorsed ( $r=.17)$. However, although it is significant, the association between age and the number of goals is weak. This is important to the research on aging because previous research had focused on the loss or decrease 
of goals in aging and this research shows that, for the list of goals created for this study, that older adults do not have this decrease.

Because the SST paradigm focuses on socioemotional goals and social partner preferences when faced with limited versus expansive time and because age is associated with a limited future time perspective (Carstensen et al., 1999), we thought that age would be associated with the type of behavioral goals endorsed. Thus, we subjected the list of 31 goals to a factor analysis, expecting that a socioemotional factor and a health factor would emerge. Although these two factors did emerge, the socioemotional factor was more similar to a general emotional well-being factor and accounted for most of the variance. Also, conflicting with SST (Carstensen et al., 1999), and hypothesis 2, age was not significantly associated with the number of emotional goals $(r=.13)$.

A second, weaker factor indexing remediation of health risks emerged. Our factor accounted for only about $7 \%$ of the variance, echoing the findings of the open-ended assessment by Rossi and Isaacowitz (2006). Although few adults in Rossi and Issacowitz’s sample spontaneously mentioned health goals, the majority did endorse health-related goals in the checklist format. Moreover, they reported age differences in the checklist-endorsed goals, with $79 \%$ of younger, $89 \%$ of middle-aged and $99 \%$ of older endorsing health goals as domains of interest. We did not see such strong effects in the current study. In fact, no age significant effects emerged for the number of health-related goals $(r=-.12)$

\section{Time and Goals}

By expanding beyond future time perspective, the current study adds to the understanding of time perspective by demonstrating both differences and similarities in the ways past, present, and future orientations influence age and goal pursuit. Some support for hypothesis 3a and 3b, 
that age would be positively associated with positive past and negatively associated with positive future, emerged in that age and time orientation were associated. There was a small significant correlation between negative past and age $(r=-.17, p<.05)$. However, age was not significantly correlated with any of the other time perspectives: positive past $(r=.11)$, positive present $(r=$ $.10)$, negative present $(r=-.10)$, positive future $(r=.00)$, and negative future $(r=-.06)$. In the current study there is little to no relationship between age and future time perspective, these results may be contrary to Pichayayothin's (2014) results showing that older adults viewed their future as more negative and less positive.

How we feel about our past is connected to our current experiences and expectations (Hendricks, 1982). Negative perceptions about the past may lead one to anticipate negative future events and may make a person less likely to pursue goals because of the thoughts of likely failure. Whereas positive perceptions about the past may lead a person to anticipate positive future outcomes and therefore have more goals for the future (Stolarski, Matthews, Posteek, Zimbardo, \& Bitner, 2014). We did see this also to be true within the correlation, that age and negative past were significantly negatively correlated.

In addition, we assessed valence of time orientation. Using the modified TAS (Pichayayothin, 2014; Mello \& Worrell, 2012), we can begin to differentiate the effects of both temporal orientation and valence. As shown in the shaded section of Table 5, the strongest bivariate associations were within time orientations, with $r$ (positive past, negative past) $=-.77, r$ (positive present, negative present) $=-.89$, and the $r$ (positive future, negative future) $=-.76$. Thus, these correlations might provide support for the continued use of Lang and Carstensen’s (2002) unidimensional conceptualization of time orientation. See Appendix 4 for additional analyses with the six time orientation combined into three orientations. The associations within a 
common valence, such as $r$ (positive past, positive present) were all moderate, ranging between $r$ $=.31$ and $r=.58$. Thus, these moderate range correlations are suggestive of a more general orientation toward positivity and negativity, which might be in line with a more stable disposition.

To examine how past, present, and future time perspectives affect the relation between age and the number of behavioral goals endorsed, we examined a series of mediation and moderation models. It is important to note that traditional statistical power analyses are problematic with these kinds of analyses (Fritz \& MacKinnon, 2007). With $\mathrm{N}=167$, we likely did have sufficient power to detect effects. However, with the multiple analyses we conducted, our likelihood of committing Type I is increased. Because our sample size is relatively small, we used bootstrapping and relied on confidence intervals to increase the stability of the betas in interpretation. With those caveats, results from the mediation tests demonstrated that negative past time perspective influenced the relation between age and number of goals. Based on the mediation analyses we see that most of the time perspectives have a direct impact on a person's goals, regardless of age, but they do not mediate the relation between age and goals. The exception to these results is when negative past is assessed. We see that negative past mediates the relation between age and the number of goals a person is currently working on, exploratory question 1a. A person who feels more negatively about their past is less likely to make goals for the future. This is less true as people age. Older adults have had a chance to reflect on their past experiences where as a younger adults have not had a chance to find meaning in the negative. According to Erikson (1982) one of the main tasks of late life is ego-integrity, being able to look back over a person's life and find satisfaction in the things that we have done. Younger adults may feel that they have failed in the past and this may be why they don't want to make more 
goals for the future because they feel they may not have had time to find meaning in past events and they are afraid they may fail again.

Contrary to other research though, a person's age was not a predictor of the other, excluding negative past, time perspectives, hypotheses $4 \mathrm{a}$ and $4 \mathrm{~b}$ and exploratory question $1 \mathrm{~b}$. And although a person's age predicted the number of goals a person was working on, once we accounted for the time perspectives (positive present, negative present, positive future, and negative future), the relationship between age and goals was no longer significant and it was a person's subjective feeling on those times that mattered more on how many goals they had for the future. Time seems to be the integral factor in understanding the number of goals a person has for their future. Zimbardo and Boyd (199) emphasis that how people feel about time has a powerful impact on how they behave, and those people may not even realize how important that influence is.

Rather than time exerting the direct and indirect effects of mediations time must also be considered in how it may interact with age to exert its full effects, exploratory question 2. Interestingly enough no research has looked at the moderating effect of age and time perspective. With these exploratory analyses we found that the moderating effects were concentrated on the highest levels of positive time (past, present, and future) and the lowest levels of negative time, but only for future). These results may, first, be very telling about the TAS (Pichayayothin, 2014; Mello \& Worrell, 2012). Even though the correlations showed highly significant associations between the subscales, these scales may not be polar opposites of each other but rather tapping into different aspects of time. From the moderation results it may be suggestive that the future subscales may be opposites but not the past or present. 
As for the conditional means in the moderation, this seems to suggest that as age interacts with time perspective only at the highest levels of positive past, positive present, and positive future. Thus, older adults with especially positive views of their past, present, and of their future pursue more goals than their younger adult counterparts, as SST would predict. This phenomenon is evident for negative future time orientation, as well. Older adults at the lowest levels of negative future time orientation have more goals relative to their younger counterparts. Thus, regarding future orientation, our results replicate those found in the SST literature.

\section{Limitations}

One of the potential limitations in the current study is that no empirically-validated list of behavioral goals was available. We compiled a list of goals suitable for screening adults into a health coaching study, thus, in focusing on domains in which we expected to observe changes related to increases in physical activity (e.g., happiness) and those for which we did not anticipate change (e.g., recycling), we may have neglected to include important behavioral goals. Moreover, by using a checklist format, we may have inflated adults' endorsement of some goals, as in Rossi and Isaacowitz (2006). Despite these limitations, however, the current study suggests that as people age they may still have many goals they want to complete and by providing them with a more comprehensive list of specific goals we may tap into that differently than by looking at only generalized domains, as most previous research has done. 


\section{References}

Baltes, P.B. \& Baltes, M. (1990). Psychological perspectives on successful aging: The model of selective optimization and compensation. In P. Baltes \& M. Baltes, (Eds), Successful aging: Perspectives from the behavioral sciences (pp.1-34). New York, NY, US: Cambridge University Press.

Baron, R. M., \& Kenny, D. A. (1986). The moderator-mediator variable distinction in social psychological research: Conceptual, strategic, and statistical considerations. Journal of Personality and Social Psychology, 51, 1173-1182. doi:10.1037/0022-3514.51.6.1173

Brothers, A., Chui, H. \& Diehl, M. (2014). Measuring future time perspective across adulthood: Development and evaluation of a brief multidimensional questionnaire. The Gerontologist, 54, 1075-1088. dio:10.1093/geront/gnu076

Carstensen, L. L. (2006). The influence of a sense of time on human development. Science, 312(5782), 1913-1915. doi:10.1126/science.1127488

Carstensen, L. L., \& Fredrickson, B. L. (1998). Influence of HIV status and age on cognitive representations of others. Health Psychology: Official Journal of the Division of Health Psychology, American Psychological Association, 17(6), 494-503. doi:10.1037/02786133.17.6.494

Carstensen, L. L., Isaacowitz, D. M., \& Charles, S. T. (1999). Taking time seriously: A theory of socioemotional selectivity. American Psychologist, 54(3), 165-181. doi:10.1037/0003-066X.54.3.165 
Carstensen, L. L., \& Lang, F. R. (1996). Future Orientation Scale. Unpublished manuscript, Standford University

Cate, R. \& John, O.P. (2007). Testing models of the structure and development of future time perspective: Maintaining a focus on opportunities in middle age. Psychology and Aging, 22, 186-201. Doi:10.1037/0882-7974.22.1.186

Coudin, G., \& Lima, M. L. (2011). Being well as time goes by: Future time perspective and well-being. International Journal of Psychology and Psychological Therapy, 11(2), 219-232.

Cross, S. \& Markus, H. (1991). Possible selves across the life span. Human Development, 34, 230-255.

D’ Argembeau, A., Renaud, O., \& Van der Linden, M. (2011). Frequency, characteristics and functions of future-oriented thoughts in daily life. Applied Cognitive Psychology, 25, 96103. doi:10.3758 /MC.38.6.809

de Volder, M.L. \& Lens, W. (1982). Academic achievement and future time perspective as a cognitive-motivational concept. Journal of Personality and Social Psychology, 42, 566571. doi:10.1037/0022-3514.42.3.566

Erdfeld, E., Faul, F., \& Buchner, A. (1996). GPOWER: A general power analysis program. Behavior Research Methods, Instruments, \& Computers, 28, 1-11. doi:10.3758/BF03203630

Erikson, E.H. (1982). The life cycle completed: A review. New York: Norton.

Elliot, A.J. \& Fryer, J.W. (2008). The goal construct in psychology. In J.Y. Shah \& W.L. Gardner (Eds.), Handbook of motivation science (pp. 235-250); New York, NY: The Guilford Press. 
Fingerman, K. L., \& Perlmutter, M. (2001). Future time perspective and life events across adulthood. The Journal of General Psychology, 122(1), 95-111. doi:10.1080/002.1995.9921225

Fung, H. H., \& Carstensen, L. L. (2006). Goals Change When Life’s Fragility is Primed: Lessons Learned From Older Adults, the September 11 Attacks and Sars. Social Cognition, 24(3), 248-278. Doi: 10.1521/soco.2006.24.3.248

Gellert, P., Ziegelmann, J.P., Lippke, S. \& Schwarzer, R. (2012). Future time perspective and health behaviors: Temporal framing of self-regulatory processes in physical exercise and dietary behaviors. Annals of Behavioral Medicine, 43(2), 208-218. Doi:10.1007/s12160$011-9312-y$

Hayes, A. F. (2012). PROCESS: A versatile computational tool for observed variable mediation, moderation, and conditional process modeling [White paper]. Retrieved from http://www.afhayes.com/ public/process2012.pdf

Hendricks, J. (1982). Time and social science: History and potential. In E.H. Muzruchi, B. Glassner, \& T. Pastorello (Eds.), Time and aging: Conceptualization and application in sociological and gerontological research. Baysid, NY: General Hall, Inc.

Lang, F. R., \& Carstensen, L. L. (2002). Time counts: Future time perspective, goals, and social relationships. Psychology and Aging, 17(1), 125-139. doi:10.1037/08827974.17.1.125

Lennings, C.J. (2000). Optimism, satisfaction and time perspective in the elderly. The International Journal of Aging and Human Development, 15, 167-181. doi:10.2190/06gk-wher-37xc-btry 
Lennings, C. \& Gow, K. (1997). Time perspective, goal setting and academic achievement in tertiary students. Journal of Applied Social Behaviour, 4, 37-51.

Lens, W., Paixao, M.P., Herrera, D. \& Grobler, A. (2012). Future time perspective as a motivational variable: Content and extension of future goals affect the quantity and quality of motivation. Japanese Psychological Research, 54(3). 321-333.

doi:10.111/j.1468-5884.2012.00520.x

Lewin, K. (1939). Field theory and experiment in social psychology. American Journal of Sociology, 44, 868-896.

Mello, Z. R., \& Worrell, F. C. (2012). The Adolescent Time Inventory: Preliminary Technical Manual. Colorado Springs, CO \& Berkeley, CA: Author.

Nurmi, J. (1992). Age differences in adult life goals, concerns, and their temporal extension: A life course approach to future-oriented motivation. International Journal of Behavioral Development, 15, 487-508.

Penningroth, S.L. \& Scott, W.D. (2012). Age-related differences in goals: Testing predictions from selection, optimization, and compensation theory and socioemotional selectivity theory. The International Journal of Aging and Human Development, 74, 87-111. doi:10.2190/AG.74.2.a

Pichayayothin, N.B. (2014). Investigating balanced time perspective in adults across the life span (Unpublished doctoral dissertation). West Virginia University, Morgantown, WV.

Powers, C. B., Wisocki, P. A., \& Whitbourne, S. K. (1992). Age differences and correlates of worrying in young and elderly adults. The Gerontologist, 32(1), 82-88. doi:10.1093/geront/32.1.82 
Rakowski, W. (1986). Future time perspective: Applications to the health context of later adulthood. American Behavioral Scientist, 29, 730-745. doi:10.1177/000276486029006007

Riediger, M. \& Freund, A.M. (2006). Focusing and restricting: Two aspects of motivational selectivity in adulthood. Psychology and Aging, 21, 173-185. Doi: 10.1037/08827974.21.1.173

Rossi, N.E. \& Isaacowitz, D.M. (2006). What is important to me right now? Age differences in domain selectivity depend on the measure. Ageing International, 31, 24-43.

Ryff, C.D. (1991). Possible selves in adulthood and old age: A tale of shifting horizons. Psychology and Aging, 6, 286-295. doi:10.1037/0882/.7974.6.2.286

Spreng, R.N. \& Levine, B. (2006). The temporal distribution of past and future autobiographical events across the lifespan. Memory \& Cognition, 34, 1644-1651. doi:10.3758/BF03195927

Stahl, S.T. \& Patrick, J.H. (2012). Adults’ future time perspective predicts engagement in physical activity. The Journals of Gerontology: Series B: Psychological Sciences and Social Sciences, 67B, 413-416. doi:10.1093/geronb/gbr118

Stolarski, M., Mattews, G., Postek, S., Zimbardo, P.G. \& Bitner, J. (2014). How we feel is a matter of time: Relationships between time perspectives and mood. Journal of Happiness Studies, 15(4), 809-827. doi:10.1007/s10902-013-9450-y

Tonn, B. E., \& Conrad, F. (2007). Thinking about the future: A psychological analysis. Social Behavior and Personality, 35(7), 889-902.

Zimbardo, P.G. (1990). Stanford time perspective orientation. Department of Psychology, Stanford University, California. 
Zimbardo, P.G. \& Boyd, J.N. (1999). Putting time in perspective: A valid, reliable individual differences metric. Journal of Personality and Social Psychology, 77, 1271-1288. doi:10.1037/0022-3514.77.6.1 
Table 1

Pearson Correlations of age and physical health goals $(N=167)$

\begin{tabular}{|c|c|c|c|c|c|c|c|c|c|}
\hline & 1 & 2 & 3 & 4 & 5 & 6 & 7 & 8 & 9 \\
\hline 1. Age & - & & & & & & & & \\
\hline 2. Lose Weight & .05 & - & & & & & & & \\
\hline 3. Gain Weight & -.07 & .06 & - & & & & & & \\
\hline 4. Increase Exercise & .09 & $.45^{* *}$ & .11 & - & & & & & \\
\hline 5. Reduce Tobacco Use & -.07 & -.05 & $.22^{* *}$ & -.04 & - & & & & \\
\hline 6. Reduce Alcohol Use & .06 & -.13 & $.17^{*}$ & -.05 & $.37^{* *}$ & - & & & \\
\hline 7. Eat Healthier Foods & .11 & $.25^{* *}$ & -.02 & $.40^{* *}$ & -.02 & .02 & - & & \\
\hline 8. Sleep More & .14 & $.40^{* *}$ & .01 & $.33^{* *}$ & .00 & .04 & $.29^{* *}$ & - & \\
\hline 9. Sleep Less & -.09 & .09 & -.03 & $.21^{* *}$ & -.02 & -.03 & $.17^{*}$ & $.30^{* *}$ & - \\
\hline 10. Walk More & .03 & .01 & .27 & .14 & .14 & .01 & -.06 & .15 & .09 \\
\hline
\end{tabular}

Note. ${ }^{*} p<.05,{ }^{* *} p<.01$ 
Table 2

Pearson Correlations of age and socioemotional development goals $(N=167)$

\begin{tabular}{|c|c|c|c|c|c|c|c|c|c|c|c|c|}
\hline & 1 & 2 & 3 & 4 & 5 & 6 & 7 & 8 & 9 & 10 & 11 & 12 \\
\hline 1. Age & - & & & & & & & & & & & \\
\hline 2. Be Kinder to Others & .10 & - & & & & & & & & & & \\
\hline 3. Be more Assertive & .05 & .23 & - & & & & & & & & & \\
\hline 4. Be more Social & -.02 & $.15^{*}$ & $.28^{* *}$ & - & & & & & & & & \\
\hline 5. Control your Anger & .13 & $.48^{* *}$ & $.28^{* *}$ & .14 & - & & & & & & & \\
\hline 6. Be Happier & .05 & $.36^{* *}$ & $.31^{* *}$ & $.36^{* *}$ & $.31^{* *}$ & - & & & & & & \\
\hline 7. Meditate or Relax & .13 & $.26^{* *}$ & $.30^{* *}$ & $.28^{* *}$ & $.25^{* *}$ & $.34^{* *}$ & - & & & & & \\
\hline 8. Develop a New Skill & .05 & $.25^{* *}$ & $.17^{*}$ & .09 & $.29^{* *}$ & .15 & $.29^{* *}$ & - & & & & \\
\hline 9. Deal with Stress Better & .06 & $.26^{* *}$ & $.29^{* *}$ & $.27^{* *}$ & $.35^{* *}$ & $.32^{* *}$ & $.44^{* *}$ & $.29^{* *}$ & - & & & \\
\hline 10. Reduce your Stress & .06 & .13 & $.22^{* *}$ & $.22^{* *}$ & $.22^{* *}$ & $.24^{* *}$ & $.48^{* *}$ & $.24^{* *}$ & $.75^{* *}$ & - & & \\
\hline $\begin{array}{l}\text { 11. Volunteer in the } \\
\text { Community }\end{array}$ & .11 & $.28^{* *}$ & $.21^{* *}$ & $.16^{*}$ & .10 & .14 & $.33^{* *}$ & $.23^{* *}$ & $.18^{*}$ & $.22^{* *}$ & - & \\
\hline $\begin{array}{l}\text { 12. Give Money to } \\
\text { Charities }\end{array}$ & $.39^{* *}$ & $.27^{* *}$ & $.24^{* *}$ & .10 & $.23^{* *}$ & $.20^{*}$ & $.24^{* *}$ & $.23^{* *}$ & $.21^{* *}$ & $.25^{* *}$ & $.40^{* *}$ & - \\
\hline $\begin{array}{l}\text { 13. Be Kinder to } \\
\text { Yourself }\end{array}$ & $.19^{*}$ & $.51^{* *}$ & $.29^{* *}$ & $.32^{* *}$ & $.36^{* *}$ & $.44^{* *}$ & $.48^{* *}$ & .11 & $.43^{* *}$ & $.36^{* *}$ & $.25^{* *}$ & $.29^{* *}$ \\
\hline
\end{tabular}


Table 3

Pearson Correlations of age and socioemotional development goals $(N=167)$

\begin{tabular}{|c|c|c|c|c|}
\hline & 1 & 2 & 3 & 4 \\
\hline 1. Age & - & & & \\
\hline 2. Appreciate Beauty & .07 & - & & \\
\hline 3. Be more Grateful & .04 & $.60^{* *}$ & - & \\
\hline 4. Be more Spiritual & $.29^{* *}$ & $.26^{* *}$ & $.25^{* *}$ & - \\
\hline 5. Be more Religious & $.31^{* *}$ & $.24^{* *}$ & $.23^{* *}$ & $.75^{* *}$ \\
\hline
\end{tabular}

Note. ${ }^{*} p<.05,{ }^{* *} p<.01$ 
Table 4

Pearson Correlations of age and socioemotional development goals $(N=167)$

\begin{tabular}{lcc} 
& 1 & 2 \\
\hline 1. Age & - & - \\
2. Make Better Decisions & .10 & $.50^{* *}$ \\
3. Improve one's Memory & $.19^{*}$ &
\end{tabular}

Note. ${ }^{*} p<.05,{ }^{* *} p<.01$ 
Table 5

Pearson Correlations of age, time perspectives, and goals $(N=167)$

\begin{tabular}{|c|c|c|c|c|c|c|c|c|c|c|c|c|c|}
\hline & $M$ & $S D$ & 1 & 2 & 3 & 4 & 5 & 6 & 7 & 8 & 9 & 10 & 11 \\
\hline 1. Age & 39.77 & 15.68 & - & & & & & & & & & & \\
\hline 2. Positive Past & 17.34 & 4.62 & .11 & - & & & & & & & & & \\
\hline 3. Negative Past & 12.72 & 5.29 & $-.17^{*}$ & $-.77^{* *}$ & - & & & & & & & & \\
\hline 4. Positive Present & 17.49 & 4.96 & .10 & $.32^{* *}$ & $-.39^{* *}$ & - & & & & & & & \\
\hline 5. Negative Present & 13.64 & 4.96 & -.10 & $-.28^{* *}$ & $.39^{* *}$ & $-.88^{* *}$ & - & & & & & & \\
\hline 6. Positive Future & 19.12 & 4.27 & .00 & $.31^{* *}$ & $-.35^{* *}$ & $.70^{* *}$ & $-.64^{* *}$ & - & & & & & \\
\hline 7. Negative Future & 10.04 & 3.97 & -.06 & $-.40^{* *}$ & $.49^{* *}$ & $-.62^{* *}$ & $.58^{* *}$ & $-.76^{* *}$ & - & & & & \\
\hline 8. Total Goals & 9.77 & 6.53 & $.17^{*}$ & $.17^{*}$ & $-.18^{*}$ & $.28^{* *}$ & $-.21^{* *}$ & $-.29^{* *}$ & $-.22^{* *}$ & - & & & \\
\hline 9. Physical Health Goals & 2.48 & 1.7 & .08 & $.20^{*}$ & $-.25^{* *}$ & $.35^{* *}$ & $-.27^{* *}$ & $.29^{* *}$ & $-.30^{* *}$ & $.68^{* *}$ & - & & \\
\hline $\begin{array}{l}\text { 10. Socioemotional } \\
\text { Goals }\end{array}$ & 4.05 & 3.24 & $.18^{*}$ & $.17^{*}$ & $-.17^{*}$ & $.22^{* *}$ & $-.19^{*}$ & $.25^{* *}$ & $-.18^{*}$ & $.93^{* *}$ & $.46^{* *}$ & - & \\
\hline $\begin{array}{l}\text { 11. Spiritual/ Religious } \\
\text { Goals }\end{array}$ & 1.31 & 1.33 & $.22^{* *}$ & .12 & -.12 & .15 & -.11 & .08 & -.06 & $.75^{* *}$ & $.39^{* *}$ & $.65^{* *}$ & - \\
\hline 12. Cognitive Goals & 0.53 & 0.77 & $.20^{*}$ & .09 & -.09 & $.22^{* *}$ & $-.21^{* *}$ & $.23^{* *}$ & -.14 & $.74^{* *}$ & $.37^{* *}$ & $.69^{* *}$ & $.58^{* *}$ \\
\hline
\end{tabular}

Note. ${ }^{*} p<.05,{ }^{* *} p<.01$ 
Table 6

Mediation regression results predicting number of goals

\begin{tabular}{lcccrc}
\hline & $b$ & $S E$ & \multicolumn{1}{l}{$t$} & $p$ & $F$ \\
\hline Age & 0.06 & 0.03 & 1.99 & .05 & $F(2,164)=4.33, p=.015$ \\
Positive Past & 0.21 & 0.11 & 1.93 & .06 & \\
\hline Age & 0.06 & 0.03 & 1.85 & .07 & $F(2,164)=4.54, p=.012$ \\
Negative Past & -0.19 & 0.10 & -2.03 & .04 & \\
\hline Age & 0.06 & 0.03 & 1.91 & .06 & $F(2,164)=8.68, p=.001$ \\
Positive Present & 0.32 & 0.10 & 3.49 & .001 & \\
\hline Age & 0.06 & 0.03 & 1.97 & .051 & $F(2,164)=5.86, p=.004$ \\
Negative Present & -0.26 & 0.10 & -2.59 & .01 & \\
\hline Age & 0.07 & 0.03 & 2.29 & .02 & $F(2,164)=10.17, p<.001$ \\
Positive Future & 0.44 & 0.11 & 3.88 & .001 & \\
\hline Age & 0.07 & 0.03 & 2.08 & .04 & $F(2,164)=6.46, p=.01$ \\
Negative Future & -0.35 & 0.12 & -2.8 & .01 & \\
\hline
\end{tabular}


Table 7

Moderation regression results predicting number of goals

\begin{tabular}{lccccc}
\hline & $b$ & \multicolumn{1}{c}{$S E$} & \multicolumn{1}{c}{$t$} & $p$ & $F$ \\
\hline Age & -0.04 & 0.12 & -0.30 & .76 & $F(3,163)=3.14, p<.05$ \\
Positive Past & -0.02 & 0.28 & -0.05 & .96 & \\
Age X Positive Past & 0.006 & 0.01 & 0.87 & .38 & \\
\hline Age & 0.11 & 0.08 & 1.45 & .15 & $F(3,163)=3.21, p<.05$ \\
Negative Past & -0.02 & 0.24 & -0.10 & .93 & \\
Age X Negative Past & -0.01 & 0.01 & -0.76 & .45 & \\
\hline Age & -0.13 & 0.12 & -1.05 & .29 & $F(3,163)=6.68, p<.01$ \\
Positive Present & -0.03 & 0.26 & -0.13 & .89 & \\
Age X Positive Present & 0.01 & 0.01 & 1.59 & .11 & \\
\hline Age & 0.06 & 0.09 & 0.65 & .52 & $F(3,163)=3.89, p<.05$ \\
Negative Present & -0.27 & 0.28 & -0.95 & .35 & \\
Age X Negative Present & 0.001 & 0.01 & 0.03 & .98 & \\
\hline Age & -0.04 & 0.15 & -0.26 & .80 & $F(3,163)=6.95, p<.01$ \\
Positive Future & 0.22 & 0.32 & 0.69 & .49 & \\
Age X Positive Future & 0.01 & 0.01 & 0.75 & .46 & \\
\hline Age & 0.12 & 0.09 & 1.47 & .14 & $F(3,163)=4.49, p<.01$ \\
Negative Future & -0.11 & 0.33 & -0.34 & .74 & \\
Age X Negative Future & -0.01 & 0.01 & -0.76 & .45 & \\
\hline
\end{tabular}




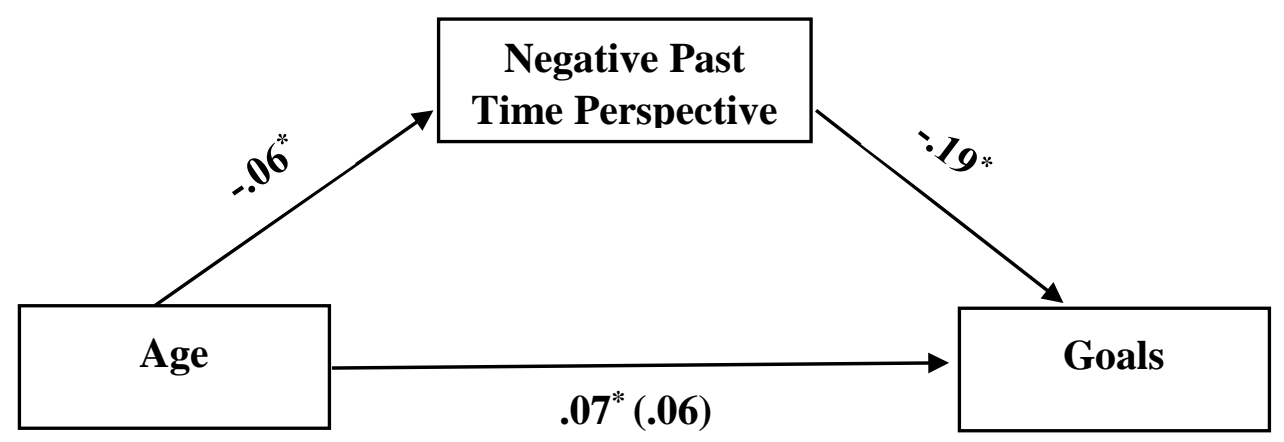

Figure 1: Significant mediation of the age to total number of goals relationship, by negative past time perspective. Note. ${ }^{*} p<.05$, 
Appendix 1.

\begin{tabular}{lll}
\hline Goals & & \\
\hline Lose Weight (1) & Study more (12) & Develop a new skill (23) \\
Gain Weight (2) & Save more money (13) & Deal with stress better (24) \\
Exercise More (3) & Spend less money (14) & Reduce your stress (25) \\
Reduce tobacco use (4) & Be kinder to others (15) & Make better decisions (26) \\
Reduce alcohol use (5) & Be kinder to yourself (16) & Improve your memory (27) \\
Walk more (6) & Control your anger (17) & Volunteer in the community (28) \\
Eat healthier foods (7) & Be happier (18) & Give money to charities (29) \\
Reduce, re-use or recycle (8) & Be more assertive (19) & Be more grateful (30) \\
Sleep more (9) & Meditate or relax (20) & Appreciate Beauty (31) \\
Sleep less (10) & Be more spiritual (21) & \\
Be more Social (11) & Be more Religious (22) & \\
\hline
\end{tabular}

Appendix 1a.

\begin{tabular}{l|l}
\hline Categories & Questions within that category \\
\hline Physical Health & $1,2,3,4,5,6,7,9,10$ \\
& $11,15,16,17,18,19,20,23,24,25,28$, \\
Socioemotional & 29 \\
Spiritual & $21,22,30,31$ \\
Cognitive & 26,27 \\
\hline
\end{tabular}


Appendix 2.

Information for factor analysis is provided below.

Types of Goals. The 31 goals were subjected to an exploratory principal components factor analysis, followed by a confirmatory factor analysis. The final analysis yielded two interpretable factors, see Appendix 1a, explaining a total of $29.93 \%$ of the variance. Items not included in the final factor loadings were any item that cross-loaded on both factors at greater than .3. Also not included were items that didn’t load onto one of the factors at .3 or greater. Of the original 31 goals, 5 were not included in subsequent analyses. These excluded goals include: being more spiritual, being more religious, giving money to charities, lose weight, and walking more

Factor 1, which accounted for $23.01 \%$ of the variance, included 21 items, broadly related to emotional well-being: be more grateful, meditate, appreciate beauty, be kinder with one’s self, be kinder with others, make better decisions, better deal with stress, reduce stress, be happier, improve memory, volunteer more, get more sleep, control one’s anger, be more assertive, eat healthier, learn new skills, increase physical exercise, save money, be more social, spend less money, and be more responsible with environmental resources. These items were combined to form a single scale indexing the strength of emotional well-being goals, which had a mean strength of 7.77 goals $(S D=5.44 ; \alpha=.88)$.

A second factor, accounting for $6.92 \%$ of the variance, was extracted. It included 5 items tapping remediate health risks such as reducing tobacco use, sleeping less, gaining weight, study more and reducing alcohol consumption. These items were combined to form a scale, with a mean of $.46(S D=.80 ; \alpha=.48)$.

\section{Mediation Hypotheses}


The relation between age and the emotional well-being goals was mediated by negative past time perspective, $F(2,164)=3.52, p=.03 ; R^{2}=.041$. Age uniquely contributed to the variance explained in negative past time perspective (path a), [ $b=-.06, p<.05]$. Negative past time perspective uniquely contributed to the variance explained in number of well-being goals (path b), [ $b=-.16, p<.05]$. Age uniquely accounted for variance in number of well-being goals (path c), $[b=.05, p<.05]$. However, when negative past was included in the model (path c'), age no longer uniquely contributed to the variance in number of well-being goals $[b=.04, p=$ .18], showing a mediation.

However, none of the other time perspectives mediated the relationship between age and goals because there was no relationship between age and those time perspectives. However, by using PROCESS, relations were still assessed, after finding that path a was not significant, using a linear regressions with age and the different time perspectives as the predictors.

The model of age and positive past significantly predicted emotional well-being goals, $F(2,164)=3.62, p=.029 ; R^{2}=.042$. However, inspection of the unstandardized betas showed that only positive past exerted direct effects on well-being goals [ $b=.19, p<.05]$. Age did not uniquely contribute to the variance accounted for in the number emotional well-being goals $[b=$ $.04, p=.15]$

Age and positive present significantly predicted number of emotional well-being goals, $F(2,164)=6.79, p=.001 ; R^{2}=.08$. However, inspection of the unstandardized betas showed that only positive present exerted direct effects on goals [ $b=.29, p<.01]$. Age did not uniquely contribute to the variance accounted for in the number of emotional well-being goals $[b=.04, p=$ $.16]$. 
Age and negative present significantly predicted number of emotional well-being goals, $F(2,164)=4.37, p=.01 ; R^{2}=.05$. However, inspection of the unstandardized betas showed that only negative present exerted direct effects on goals $[b=-.20, p<.05]$. Age did not uniquely contribute to the variance accounted for in the number of emotional well-being goals $[b=.04, p=$ .15].

Age and positive future significantly contributed to the variance accounted for in the number of well-being goals, $F(2,164)=8.89, p<.001 ; R^{2}=.10$. Inspection of the unstandardized betas showed that only positive future exerted direct effects on goals $[b=.36, p<.01]$. Age did not uniquely contribute to the variance accounted for in the number of emotional well-being goals $[b=.05, p=.08]$.

Age and negative future significantly contributed to the variance accounted for in the number of current goals, $F(2,164)=5.08, p<.01 ; R^{2}=.06$. Inspection of the unstandardized betas showed that negative future exerted direct effects on goals $[b=-.28, p<.01]$. Age did not uniquely contribute to the variance accounted for in the number of emotional well-being goals [ $b$ $=.04, p>.05]$.

\section{Moderation Hypotheses}

Examining whether positive past and negative past moderated the effect of age on emotional well-being goals, no significant effects were found, $F(3,163)=2.62, p>.05$ and $F(3,163)=2.45, p<.05$, respectively.

In the equation examining whether positive present moderated the effects of age on emotional well-being goals, an omnibus effect was detected $\left[F(3,163)=3.14, p<.05, R^{2}=.08\right]$. However, neither positive present $[b=.04, p=.85]$, age $[b=-.08, p=.46]$, nor the interaction $[b$ $=.01, p=.26]$ uniquely contribute to the overall effect. 
Similarly, moderating effects examining negative presents effect on the relation between age and the number of emotional well-being goals, an omnibus effect was detected $[F(3,163)=$ 3.02, $\left.p<.05, R^{2}=.05\right]$. However, neither negative present $[b=-.33, p=.16]$, age [ $b=-.004, p=$ $.96]$, nor the interaction $[b=.003, p=.56]$ uniquely contribute to the overall effect.

In the equation examining whether positive future moderated the effects of age on emotional well-being goals, an omnibus effect was detected $\left[F(3,163)=6.03, p<.05, R^{2}=.10\right]$. However, neither positive future $[b=.21, p=.42]$, age $[b=-.03, p=.82]$, nor the interaction $[b=$ $.004, p=.55]$ uniquely contribute to the overall effect.

Similarly, moderating effects examining negative futures effect on the relation between age and the number of emotional well-being goals, an omnibus effect was detected $[F(3,163)=$ $\left.3.44, p<.05, R^{2}=.06\right]$. However, neither negative future $[b=-.16, p=.56]$, age $[b=.07, p=$ $.32]$, nor the interaction [ $b=-.003, p=.65]$ uniquely contribute to the overall effect. 
Appendix 3.

\section{Additional Results}

\section{Mental Health and Chronic Conditions}

A person's mental health, using the SF12, and physical health, using the number of chronic conditions, were assessed as predictors and potential mediators/moderators for the number of goals a person has, beyond age and time perspective.

Using a linear regression, mental health was a significant predictor of number of goals, $F(1,165)=9.67, p=002, R^{2}=.24$. This shows that a person's mental health plays a significant role in understanding if a person is willing to committee to goals, looking towards the future.

With mental health being a predictor of the number of goals a person is currently working on, the mediation effects of mental health were then assessed. The relation between age and the total number of goals showed a significant indirect effect through mental health, $F(2,164)=6.21$, $p=.003 ; R^{2}=.070$. Age uniquely contributed to the variance explained in mental health, [b= $.11, p<.05]$. Mental health uniquely contributed to the variance explained in goals, $[b=-.17, p<$ $.05]$. Age did not uniquely contribute to the variance of goals $[b=.05, p>.05]$. This shows that the relationship between age and goals is via the indirect effect of a person's mental health.

Using a linear regression, the number of chronic conditions did not significantly predict the number of goals a person is currently working on, $F(1,165)=1.835, p>.05$. A person's physical health does not seem to predict the number of current goals.

Age, number of chronic conditions, and time perspective were used to predict the number of goals. Although chronic conditions were assessed as a moderator between age and all time 
perspectives, only the present time perspectives were found to be significant and are the only ones discussed. Considering a moderated mediation between age, chronic conditions, time perspective and total number of goals showed significant results for the positive present time perspectives. In the equation examining whether number of chronic conditions moderated the effects of age on positive present time perspective, an effect was detected $[F(3,163)=3.72, p<$ $\left..05, R^{2}=.064\right]$. However, age [ $\left.b=.01, p=.69\right]$ did not uniquely contribute to the overall effect. Number of chronic conditions [ $b=-3.67, p=.003]$, and the interaction of age and positive present time perspective [ $b=.06, p=.008]$ uniquely contribute to the overall effect. In assessing the mediation effect of age and positive present on goals a significant effect was detected, $F(2,164)=8.68, p<.05, R^{2}=.096$. Positive present uniquely contributed to the variance explained in goals, $[b=.34, p<.05]$. Age did not uniquely contribute to the variance of goals [ $b$ $=.06, p>.05]$.

Considering a moderated mediation between age, chronic conditions, time perspective and total number of goals showed significant results for the negative present time perspective. In the equation examining whether number of chronic conditions moderated the effects of age on negative present time perspective, an effect was detected $\left[F(3,163)=3.13, p<.05, R^{2}=.05\right]$. However, age [ $b=-.02, p=.44]$ did not uniquely contribute to the overall effect. Number of chronic conditions [ $b=3.19, p=.009]$, and the interaction $[b=-.05, p=.03]$ uniquely contribute to the overall effect. In the assessing the mediation effect of age and positive present on goals a significant effect was detected, $F(2,164)=5.86, p<.05, R^{2}=.07$. Positive present uniquely contributed to the variance explained in goals, [ $b=-.36, p<.05]$. Age did not uniquely contribute to the variance of goals $[b=.06, p>.05]$. These results seem to suggest that chronic 
conditions, physical health, may be the reason for the relations between age and time perspective and that health may be why time mediates/moderates the age effects on goals. 
Appendix 4.

To assess whether the time orientation scale should be three measurement instead of six, the negative orientations were reverse coded and combined with the positive orientations to create three scales: total positive past, total positive present, and total positive future.

Correlations with the combined time perspectives, age and the goal domains were assessed. See Table 8 for correlations. Results for the three time perspectives were similar to the results, of the correlations, with the six time perspectives. This may be an indication of overall time instead of valanced time. Further analyses were not rule due to sample size but may be a direction for future research. 
Table 8

Pearson Correlations of age and socioemotional development goals $(N=167)$

\begin{tabular}{|c|c|c|c|c|c|c|c|}
\hline & 1 & 2 & 3 & 4 & 5 & 6 & 7 \\
\hline 1. Age & - & & & & & & \\
\hline 2. Total Positive Past & .14 & - & & & & & \\
\hline 3. Total Positive Present & .11 & $.39^{* *}$ & - & & & & \\
\hline 4. Total Positive Future & .04 & $.45^{* *}$ & $.70^{* *}$ & - & & & \\
\hline 5. Physical Health Goals & .08 & $.23^{* *}$ & $.32^{* *}$ & $.31^{* *}$ & - & & \\
\hline $\begin{array}{l}\text { 6. Socioemotional } \\
\text { Development Goals }\end{array}$ & $.18^{*}$ & $.18^{*}$ & $.22^{* *}$ & $.23^{* *}$ & $.46^{* *}$ & - & \\
\hline $\begin{array}{l}\text { 7. Spiritual/ Religious } \\
\text { Goals }\end{array}$ &. $.23^{* *}$ & .14 & .13 & .08 & $.39^{* *}$ & $.65^{* *}$ & - \\
\hline 8. Cognitive Goals & $.18^{*}$ & .09 & $.22^{* *}$ & $.20^{*}$ & $.37^{* *}$ & $.69^{* *}$ & $.57^{* *}$ \\
\hline
\end{tabular}

Note. ${ }^{*} p<.05,{ }^{* *} p<.01$ 